\title{
Research on the Development Situation and Countermeasures of Innovative Industrial Clusters in Xiangyang High-tech Zone
}

\author{
Guohua Chen ${ }^{1}$, Bo $\mathrm{Li}^{2, *}$ and Haiying $\mathrm{Hu}^{3}$
}

School of Mechanical Engineering of Hubei University of Arts and Science, Xiangyang, China 159782071@163.com, ${ }^{2113711891 @ q q . c o m, ~}{ }^{3} 183924385 @ q q . c o m$

${ }^{*}$ Corresponding author

Keywords: High-end equipment, Innovative, Industrial clusters; Development Situation, Countermeasures

\begin{abstract}
Taking automotive industry as the object, through in-depth investigation of the development situation of the high-end equipment manufacturing industry in Xiangyang High-tech Zone, its industrial foundation, industrial chain foundation and industrial cluster foundation are all analyzed, then the existing problems are pointed out. Next, the major tasks, promotion mechanisms and countermeasures for construction are clearly defined, which provides theoretical guidelines and practical lessons for the innovative industrial clusters in Xiangyang High-tech Zone.
\end{abstract}

\section{襄阳高新区高端装备创新型产业集群发展现状及对策研究}

\author{
陈国华 ${ }^{\mathrm{a}}$, 李波 ${ }^{\mathrm{k}}$, 胡海荣 ${ }^{\mathrm{c}}$ \\ (湖北文理学院机械工程学院, 襄阳, 湖北, 中国) \\ a59782071@163.com, b113711891@qq.com, ${ }^{c 183924385 @ q q . c o m ~}$ \\ *通讯作者
}

关键词：高端装备；创新型；产业集群；现状；对策

中文摘要. 以汽车产业为对象, 通过对襄阳高新区高端装备制造业现状进行深入调研, 分析 了襄阳高新区产业基础、产业链基础、产业集群基础及存在的问题, 然后明确建设的主要任 务、推进机制及对策措施，为襄阳高新区创新型产业集群提供了理论指南和现实借鉴。

\section{1. 引言}

21 世纪以来, 经济的全球化以及具有行业特色的产业集群现象并行不悖的发展, 对世界 各地经济产生了深刻的影响。在全球范围内那些成长快速的区域, 通常是以一个或几个产业 为核心，大量产业联系密切的企业及相关支撑机构在空间上集聚，从而使该地区形成参与国 际竞争强劲而持续的竞争优势。因此, 产业在特定空间上的集聚而形成的产业集群作为一种 产业组织的新形势 ${ }^{[1-2]}$, 引起了人们的广泛关注, 成为政界、工业界、经济界研究的一个重要 主题 ${ }^{[3-4]}$ 。

20 世纪末期, Jorg Meyer等认为产业集群的形成动力是技术创新、非正规学习、合作竞争、 知识共享和溢出等 ${ }^{[5]}$ 。20世纪初期, Swann将产业集群的动力机制概括为包括产业优势、新企 业进入、企业文化增长、文化资本等共同作用的正反馈系统 ${ }^{[6]}$ 。Engelstoft通过对丹麦产业集 群的理论与实证研究，认为集群内的企业竞争在竞争与合作的机制和共同奋斗目标下能够实 现风险共担、互相支持，有利于企业间的相互学习和创造力提高 ${ }^{[7]}$ 。Behrens和Thisse则研究 了市场规模差异与组织成本不对称性情况下，市场在哪里导致过度集聚，规划者就在那里选 
择非对称的组织成本，甚至更多的集聚，当消费者对多样化的边际偏好高时，规划者总是偏 爱拥有更大集聚规模大国的较低的组织成本, 否则, 规划者总是偏爱拥有较小集聚规模的大 国的较低的组织成本 ${ }^{[8]}$ 。

在高端装备制造业的研究中, 国外学者主要集中在技术的重要性、技术创新、政府的研 究资助、R\&D活动以及影响先进装备制造业发展的因素等方面。Sajid Anwar和MingliZheng 通过政府对机械装备产业、电力设备产业和运输装备产业的研发资助对其产业发展影响, 得 出政府的研发投资波动对装备制造业的发展有很的的影响 ${ }^{[9]}$ 。Tom Conger和Denise Chiavetta 总结了未来十年内装备制造业要在七方面突破, 才能实现制造业健康发展, 即有计划的培养 高素质人才、制定技术标准和技术路标、在不同领域的技术交叉中改造创新、注重不同行业 技术相互循环促进、营造良好的产业政策环境、扩大生产销售网络并实现多国运营或全球化 战略、促进各供应链交叉融合形成供应网络 ${ }^{[10]}$ 。

与国外产业集群研究相比, 国内产业集群开始大量研究则是2000年以后, 起步较晚, 研 究内容较零散, 缺乏系统的理论探索和实证研究。总体上看, 目前中国学者对产业集群的研 究主要集中于对产业集群的内涵、新特点、发展模式、动力机制、如何提高企业的生产率以 及区域效率等方面进行研讨。

\section{2. 发展现状}

\section{1 产业基础}

襄阳作为老工业基地, 经过多年发展, 具备较雄厚的产业基础。全市装备制造业已形成 门类较齐全, 具有一定规模和技术水平的产业体系, 并发展出一批特色产业集群, 不仅在全 省产业布局中占有重要地位，在全市产业发展格局中也占有举足轻重的地位。

目前, 全市装备制造业已经初步形成了以航空航天、轴承及基础件、轨道交通装备、数 控机床、钢结构等为特色的产业集群, 其中轴承、软启动设备已经纳入省重点发展产业集群。 同时, 航空航天产品技术水平居国内领先地位, 航天救生装备、航天座椅等产品具有核心竞 争力, 初步形成了以航宇公司、航天42所为龙头的航空航天产业集群; 轴承及基础件为传统 优势产业, 发展势头强劲, 形成以襄轴、新火炬、鹰牌、新兴联等为龙头的轴承产业集群; 轨道交通装备初步形成了以金鹰工业园、南车工业园为核心，以中铁十一局集团第六工程公 司、中国南车集团襄栎电机、时瑞达重工为重点的轨道交通装备产业集群; 数控机床产业形 成了以珠江数控、兆山集团襄阳机床、万盟数控为核心的数控机床产业集群; 电气设备制造 业以软启动为特色, 形成了以大力电工、追日电气、万洲电气等为代表的软启动产业集群; 金属制品业形成了以美亚达集团、浩南集力为核心的产业集群。节能环保装备、智能装备、 农业机械、工程机械等一批具有特色的产业集群倠形已初步形成。

2017年襄阳市实现地区生产总值3694.5亿元 (现价), 全市规模以上工业增加值增长 $10.1 \%$

(可比价)。其中, 轻工业增加值增长 $8.7 \%$, 重工业增加值增长 $10.9 \%$ 。全市规模以上工业 企业个数达到1877家, 比上年净增113家。其中, 产值过亿元的企业1204家, 过十亿元的企业 121家, 过五十亿元的企业9家, 过百亿元的企业3家。汽车产业实现产值 2160.2 亿元, 增长 $6.6 \%$; 农产品加工业实现产值 2277.3 亿元, 增长 $9.9 \%$; 装备制造、医药化工、电子信息、新能源新 材料、新能源汽车产业分别实现产值 1034.2 亿元、650.3亿元、496.8亿元、265.5亿元和150.4 亿元, 分别增长 $11.4 \% 、 10.2 \% 、 9.3 \% 、 11.3 \%$ 和 $21.5 \%$ 。全市规模以上工业企业实现主营业务 收入 5738.5 亿元, 增长 $10.0 \%$ 。实现利税 433.0 亿元, 增长 $3.0 \%$, 其中, 利润总额 295.4 亿元, 增长 $3.8 \%$ 。 


\section{2 产业链基础}

襄阳高端装备产业集群能够形成产业链, 整个产业链上游有零部件供应商, 下游是高端 装备制造企业, 侧面则延伸到互补产品的制造商和专门基础设施的供应者。这些企业积聚在 一起，能使厂家更有效地获得各种资源，提高资源的利用效率，发挥资源集聚效应。

襄阳高新区高端装备创新型产业集群依靠上游武钢襄阳重型装备材料有限公司、襄阳宇 清传动科技有限公司、襄阳汽车轴承股份有限公司等国务院国资委直属的国有特大型企业、 国家级高新技术企业, 保证了原材料、通用基础件、专用零部件、金属制品及其他配套功能 部件等的供给。通过珠江数控集团 (襄阳) 有限公司、中日龙 (襄阳) 机电技术开发有限公 司、航宇救生装备有限公司等实力雄厚的企业的技术支持和装备保证, 保证了其生产过程所 需的基础设施以及先进技术。下游产业的发展需求是中游产业发展的重要动力和方向。目前 在国内装备行业的下游主要是汽车行业、机械行业和军工行业。而衰阳高新区高端装备创新 型产业集群通过东风汽车有限公司（DFL）、东风德纳车桥有限公司、湖北中航精机科技股 份有限公司等企业的市场需求, 使其中上游企业的产品得以流入市场, 保证了物资的流动, 推动了产业链的发展。

\section{3产业集群基础}

襄阳高新区高端装备制造产业集群经过多年的结构调整和发展创新, 形成了门类较齐全, 具有一定规模和技术水平的产业体系, 并发展出一批特色产业集群, 不仅在全省产业布局中 占有重要地位, 在全市已经初步形成了以航空航天、轴承及基础件、轨道交通装备、数控机 床、钢结构等为特色的产业集群。高新区规模以上装备制造业企业132家，占全市规模企业以 上企业总数的 $10.5 \%$ ，工业产值过亿元企业51家。装备制造业已成为襄阳市 “一个龙头、六大 支柱” 产业发展格局中的 “六大支柱” 产业之一，成为衰阳市工业经济发展的重要支柱。

襄阳高新区以汽车产业为基础, 大力培养扶持高端装备制造产业, 经过多年发展, 已初 步形成区域优势明显、行业地位显著、企业创新能力突出、产业特色鲜明的高端装备产业集 群。

\section{4存在的问题}

（1）生产工艺有待改进, 配套加工能力不强

装备制造产业属于资金密集型、技术密集型产业，其装备水平、工艺水平，直接决定了 产品品牌与质量。由于我市多数装备企业在在特种工艺的研发上投入较少, 同时零部件制造 设备大部分是九十年代及二零年代初水平, 少部分企业近几年通过技改的支持, 加工能力有 所提高, 但是高精度的加工能力依然不够, 军工齿轮、锻造、高精度模具、精密液压件、精 冲模具钢、高水平的轴承零部件、工件表面淬火热处理等本地难以满足。

(2) 企业家的创新能力、工匠精神需要提升

尽管已经建立各种交流平台，有近两百家企业、科研单位加入，但是同行之间交流不够， 信息流通依然不畅, 本地企业大多独自为战, 对行业带动作用有限。同时企业家对创新认识 不足, 由于企业长期利润低, 缺乏相应的创新投入, 导致精品缺失。以责任、担当等为导向, 而不是以个人利益为导向的企业家精神、专注实业的工匠精神以及前卫的市场观念都有待进 一步引导和培育。

\section{（3）人才以及熟练技工缺失}

钳工电工缺乏、机械设计人才流失、高端开发和应用人才不足。襄阳作为3-4线城市，社 会福利, 工资待遇与大城市相比还有差距, 机遇较少, 很难留住人才, 以至于在产品上模仿 较多，原创较少，产品生命周期不长或更新换代跟不上。

（4）支持创新的体制机制有待完善 
以市场为导向、企业为主体, 大专科研院校相互协同, 推动科研成果落地的创新体系还 没有形成。

\section{3. 发展对策}

\section{1重点任务}

（1）统筹产业集群发展科学布局

落实国家、湖北省及襄阳市产业政策, 遵循产业发展内在规律, 结合现有基础和优势, 组建国家级工业发展咨询团队, 统筹规划高新区高端装备产业链的空间布局, 积极推动以产 业链为纽带、资源要素集聚的智能制造装备产业集群建设, 加强规划引导, 完善汽车产业园、 深圳工业园、佳海工业园等产业链协作配套体系, 促进产业集聚区规范有序发展, 以集群培 育带动全区产业创新能力整体提升。

(2) 完善产业集群创新链

以襄阳华中科技大学先进制造工程研究院为基础, 引入国家重点科研机构、知名高校、 以及襄阳本地院校等优势资源, 联合组建 “襄阳高新区汽车高端装备产业技术创新联盟”, 打造具有地区影响力的研发中心、检测中心、标准中心和信息中心, 提升装备产业集群的整 体竞争优势。

（3）推进产业集群上下游企业协同发展

按照产业链上下游协同创新需要, 设定国家、省级科技创新平台后建设补助项目，布局 重点实验室、工程实验室、工程(技术)研究中心、企业技术中心、产业技术研究院等重大技 术创新平台的建设。鼓励支持骨干企业牵头, 与襄阳本地研发机构、中小企业联合组建技术 创新战略联盟, 协同开展集群关键共性技术攻关, 共同承担重大科技攻关任务, 参与国家和 省科技计划实施。鼓励支持骨干企业在集群内投资兴办专业化捊化器, 协助提升其市场化运 营水平和融资能力。

(4) 加强产业链核心企业培养

核心企业是产业集群形成和发展的重要基础, 是产业集群升级的带动力量。围绕襄阳高 新区传统汽车及新能源汽车产业, 通过产业链重大发展专项经费, 重点支持高端装备产业链 上下游的发展，按照 “中部地区规模、技术、管理、效益 4 个一流” 的标准，引进培育一批龙 头骨干企业和核心配套企业, 充分发挥其在产业集群建设中的集聚带动效应, 逐步建成行业 领先、具有自主创新和系统集成能力、具有参与国际市场分工能力的大型企业集团, 衍生和 吸引更多相关企业集聚高新区。

(5) 产业链关键技术与产品创新

针对高新区汽车高端装备产业链的发展需求, 通过重大科研项目经费定向支持省内外知 名高校、科研机构等开展创新性机械结构的设计、绿色制造技术、智能制造技术、节能制造 技术、等关键技术的研究。发展武钢襄阳重型装备材料有限公司的钢材锻造技术、热处理技 术, 襄阳汽车轴承股份有限公司的各类轴承的设计与制造技术, 珠江数控集团（襄阳）有限 公司的机床数控技术, 中日龙 (襄阳) 机电技术开发有限公司的工业自动装置控制技术, 东 风汽车有限公司 (DFL) 的汽车整车设计与制造技术、成套生产线技术等产业链中优势企业 的关键技术。

(6) 推动产业链重大项目建设

对接国家重点投资领域、长江经济带发展规划纲要、国家 “十三五” 规划、国家产业投 资基金、国家老工业基地改造政策、国家重大改革部署, 通过产业链重大项目配套经费, 积 极策划产业链争取一批国家重大投资项目和改革创新试点, 增强产业集群发展后劲, 突出结 构优化调整, 促进一批综合效益好、带动性强的大型产业项目在集群落地, 引导企业按产业 
链上、下延伸, 带动一批配套项目, 拓展产业聚集发展空间, 培育形成优势产业集群发展新 的增长点。

\section{2政策措施}

（1）强产业链组织管理，完善协调发展机制

瞄准国内外先进技术, 成立由高新区、企业、院所等相关单位共同组成的汽车高端装备 产业链建设领导小组, 统领产业链建设工作全局, 加快产业链龙头骨干企业和中小企业共同 发展，促进产品结构优化调整和产业技术升级。

成立汽车高端装备创新型产业集群建设的工作机构, 负责产业集群日常事务, 按照规划 落实集群建设的重点任务, 具体组织项目申报、企业培育、融资担保、招商引资、人才引进、 品牌建设, 以及政府部门任务协调工作。积极构建以市场为导向、以企业为主体、产学研相 结合的产业技术创新战略联盟，集中优势力量攻克阶段性行业关键共性技术和难题。

完善与科技部、湖北省科技厅、襄阳市科技局等会商工作机制，争取国家、省科技重大 专项、重大科技基础设施和各类重大科技计划在产业集群落地实施。

(2) 产业集群发展资本投入，形成多层次金融扶持体系

在整合现有政策资源和资金渠道的基础上，设立产业集群专项资金，建立覆盖创新研发、 转化孵化、市场应用等多环节的资金支持体系，加大对产业集群发展急需的技术研发、创新 平台、创新人才的支持力度。通过政府增信, 争取国家政策银行、商业银行对产业链基础设 施及重大产业化项目给予信贷支持。

设立科技成果转化先导资金，面向科技型小微企业发展创业投资机构，开展天使投资、 创业投资，解决好企业发展的 “最初一公里” 问题。强化科技金融服务，综合运用科技保险、 科技担保、知识产权质押等手段，推动集群加速发展。

（3）创新政策,优化创新创业环境

积极落实中央、湖北市、襄阳市出台鼓励自主创新的政策措施,在全面落实现行各项促进 科技投入和科技成果转化、支持高技术产业发展等方面税收政策基础上，结合税制改革方向 和税种特征, 研究完善鼓励创新、引导投资和消费的税收支持政策,加大研发经费加计扣除、 高新技术企业所得税优惠、技术交易税收优惠等政策落实情况的督查力度。加强政策的相互 衔接及配套落实，完善鼓励创新政策体系。在申报国家、省市科技型中小企业创新资金项目 中优先推荐集群区内技术含量高、具有自主知识产权的企业和项目, 促进集群区内中小企业 快速成长

（4）知识产权保护，提供全方位服务

加大对集群知识产权管理力度，开展行业、产业专利态势分析和重大经济科技活动知识 产权分析评议。不断提高产业集群企业的专利拥有量, 培育一批拥有核心技术、自主知识产 权和品牌的骨干企业, 提高其核心竞争力。优先建立集群知识产权信息服务网络, 为集群企 业申请、授权及开展知识产权质押融资业务提供全方位服务。坚决查处和打击各种知识产权 侵权行为，提高产业集群企业运用及保护知识产权能力。

（5）加大高层次人才引进力度，提升人才培养能力

建立高端人才引进机制, 加大海外高层次人才和团队的引进力度, 为科技创新和产业发 展提供人才支持。进一步完善人才激励机制, 既要为人才创造良好的工作与生活条件, 也要 形成竞争与鼓励创新的氛围, 使资源配置向创新能力强的人才倾斜, 优厚条件吸引海内外人 才，制定灵活高效的用人机制。

（6）开放创新合作，塑造产业集群品牌

促进汽车高端装备产业集群主动与国内外优质创新资源链接。鼓励集群企业瞄准世界前 沿技术, 通过人才引进、技术引进、合作研发、委托研发、建立联合研发中心、专利交叉许 可等方式开展国内外创新合作, 有重点地建设国际技术转移机构和国际科技合作基地, 增强 自主创新能力。加强集群与国家自主创新示范区、高新技术产业开发区和各省市高水平集群 
的科技创新资源共享和产业链合作, 通过联合孵化项目, 共建产业基地, 推动集群产业链横 向拓展和纵向延伸，形成完整的核心产业链和技术链，提高集群持续发展能力。

\section{3推进机制}

\section{(1) 加大项目推进力度}

按照行业路线图，推动项目接续滚动发展。重点领域、重大项目要明确牵头单位和责任 领导, 负责政策制定、项目跟踪推进等。引导项目建设单位科学安排项目推进计划和工作方 案, 绘制工作网络图和相关图表, 明确进度节点, 落实责任人, 确保按计划步骤推进。对进 度滞后的项目建设单位, 各级各部门要对照施工合同, 加强督促指导, 促进项目加快建设进 度。

（2）完善督查落实机制

坚持实事求是和为决策服务的原则, 把上级重大决策、重要工作部署和重点工作贯彻落 实情况作为督促检查的重点, 做到事事有着落。高新区直各有关部门和各区政府、各管委会 要建立健全上下联动、部门协调的工作推进落实机制, 加强跟踪分析和督查落实, 推动产业 健康快速发展。

\section{4. 结束语}

本文从理论分析入手, 以经济理论为指导, 借鉴产业经济学、区域经济学等学科有关理 论, 在深入实际调查研究的基础上, 综合分析襄阳高端装备制造业产业集群现状及存在的问 题, 明确政府在培育发展汽车制造高端装备产业集群中的作用, 提出合理化对策, 为襄阳高 新区创新型产业集群提供理论指南，促进襄阳高新区汽车高端装备产业发展。

\section{致谢}

本文为湖北省技术创新专项（软科学研究项目：2018ADC077）阶段性成果之一。

\section{References}

[1] Ruan Jian Qin, Shi Qi, Zhang Xiaobo. Dynamic Evolution of Industrial Clusters and Local Government Policy[J].Management World, 2014(12):79-91.

[2] Wang Fujun, Shen Songdong. The Comparison of the Equipment Manufacturing Industry in the U.S., Japan and Korea and Its Enlightenment[J]. Journal of Central China Normal University (Humanities and Social Sciences Edition), 2012,51(03):38-46.

[3] Lv Yongquan. Study on the Development of High-end Equipment Manufacturing Industry in China[J]. Economic and Social Development, 2015,13(03):1-4+87.

[4] Peng Donglin. Research on Hubei Automobile Industry Based on Cluster Development[J]. Financial economy, 2015,13(03):1-4+87.

[5] Jorg Meyer, Martin, Michael. Industrial Clusters Knowledge Integration and Performance[J].World Development, 1998(32).

[6] Swann. Towards a competence theory of the region[J].Cambridge Journal of Economics, 1999(23).

[7] Engelstoft. The competence of clusters in Denmark[J].International Business Research,20016(15).

[8] Behrens, Thisse. Organization cost influence on Industrial Cluster[J].The Belknap Press of the Harvard University Press.Cambridge,2006(63). 
[9] Sajid Anwar, Mingli Zheng. Government spending on research and development and industrial production in Singapore[J].International Journal of Asian Management,2004(24).

[10]Tom Conger, Denise Chiavetta. The pulse of industry cluster[J].Industrial Engineer,2006(11). 